\title{
THE PROBLEM OF CHOICE OF THE GROUND LASER SCANNER
}

\author{
D. Gura ${ }^{1}$, G. Shevchenko² , A. Shirokov ${ }^{3}$ \\ DOI: http://doi.org/10.15350/L_26/8/21/21
}

\begin{abstract}
Laser scanners have appeared in Russia about ten years ago and immediately gained great popularity among the various surveying. But use them in full is only about $20-25 \%$ of the organizations. Other organizations that are also scanners that use them do not fully, if them something missing. Most often, this software equipment, training, and more, but the most fundamental reason is related to improper purchase equipment at the primary level.
\end{abstract}

Keywords: ground laser scanner; angular accuracy; tilt compensator; georeferencing; "Effective range"; the engineering geodesy; industry.

При выборе сканера учитывают сферу применения прибора. Это могут быть сферы: архитектура и реставрация (создание объемных чертежей фасадов и интерьеров); промышленность (создание трехмерных моделей производства); топография (создание плоского топографического плана, а также цифровых моделей рельефов); инженерная геодезия (сферы, где требуется высокая точность и детальность съемки).

Первое что нужно учитывать - это качество данных, которое может выдавать сканирующая система. [1] Под качеством следует подразумевать:

1)Точность дальномера

2)Угловая точность

3)Размер пятна лазера (расходимость луча)

4)Компенсатор (сенсор) наклона

5)«Шумовые» измерения

Благодаря этим характеристикам, возможно получить максимальный тип данных в конечном результате. Обсудим каждый из этих параметров.

Точность дальномера. [2. с. 25] У всех сканеров оно обозначено поразному. Точность дальномера зависит от отражающей способности. Точность включает в себя такой параметр как «качество данных». Этот параметр характеризует увеличение точности за счет усреднения нескольких измерений. Т.е. делается не одно измерение на точку, а несколько (от 1 до 16 и даже до 32). Но этот процесс влияет на время съемки, а это значит, что скорость съемки при высоком качестве, может в 10 раз быть ниже съемки, чем при низком качестве.

1 Dmitry Gura, Candidate of Technical Sciences, Senior Lecturer, Kuban State Technological University, Russia.

2 Grittel Shevchenko, assistant, Kuban State Technological University, Russia.

${ }^{3}$ Aleksandr Shirokov, student, Kuban State Technological University, Russia. 
Угловая точность. [3 с. 171] Угловая точность - оказывает существенное влияние на точность данных при увеличении расстояния до объекта (особенно влияет при измерении на больших расстояниях). Этот параметр в технических характеристика указывают не все производители. Диапазон угловой точности колеблется от 6 до 25 секунд.

Размер пятна лазера - оказывает существенное влияние на детализацию данных при увеличении расстояния до объекта (рис. 1). Диапазон может составлять от 0.1 до 0.35 мрад. [4 с. 89] Также не пишется у многих производителей в технических характеристиках. При выборе сканера мало кто обращает внимание на данный тип характеристик, хотя он представляет собой особую важность.

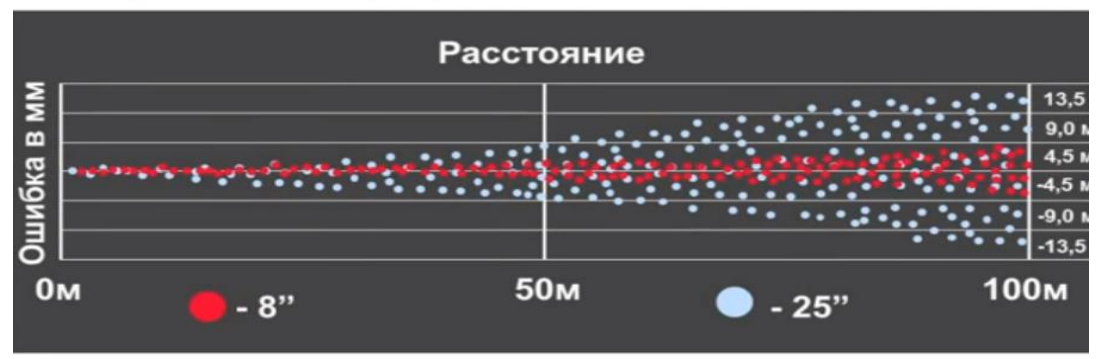

Рис. 1. Размер пятна лазера в зависимости от расстояния

Компенсатор/сенсор наклона. Компенсатор: оказывает непрерывную компенсацию наклона инструмента в процессе сканирования. Сенсор: одно- (двух-) кратное измерение наклона инструмента до (до и после) сканирования. Выбрать прибор с компенсатором было бы правильнее, т.к. компенсатор в процессе сканирования работает постоянно, а сенсор срабатывает только 1, или 2 раза (только вначале, или вначале и в конце).

Также необходимо учитывать дальность. Говоря о дальности, нужно помнить о качестве данных. Поэтому следует обращать внимание не просто на максимальную дальность, а на дальность при отражающей способности.

Немало важна скорость работы. Скорость работы включает в себя:

1)Скорость самого сканера

2)«Эффективная» дальность

3)Угол обзора

4)Геопривязка данных в поле.

Скорость лазерного сканера. Большинство современных приборов на рынке имеют от 10000 до 1 млн. измерений в секунду. [5 с. 53] Благодаря такому количеству сканированных точек, получается высокоточные результаты. Т.е. чем больше точек сканер сможет зафиксировать в 1 секунду времени, тем выше будет качество полученного изображения выше.

«Эффективная» дальность. При съемке на открытом пространстве, сканер с большей дальностью требует меньшее количество установок станций, благодаря этому можно ускорить время проведения работ (если сканер дальнобойный) (рис.2). 


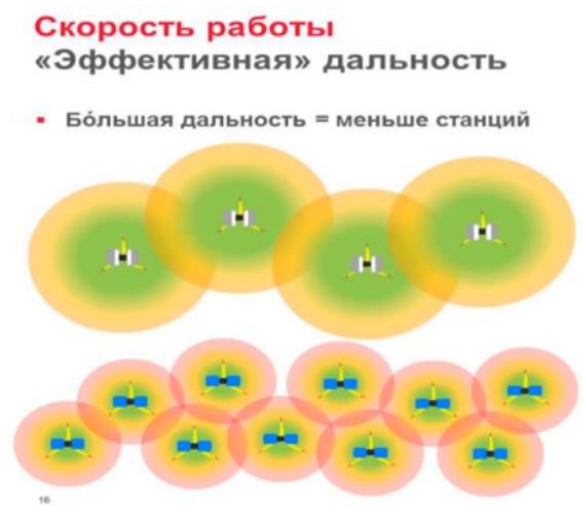

Рис. 2. Зависимость количества станций от дальности измерений

Угол обзора. Сканировать здания изнутри сканером с полным углом обзора удобнее, чем сканером с ограниченным углом обзора.

Геопривязка данных в поле - параметр очень важный. Т.к. проекты бывают очень разнообразны, и далеко не всегда простые способы привязок работают быстрее или вообще, бывают ли доступны, то нужно будет задуматься над этим вопросом. [6 с. 76] Для подобного случая геопривязки нужно выбирать сканер, который будет позволять осуществлять геопривязку путем загрузки координат в сам сканер (рис. 3).

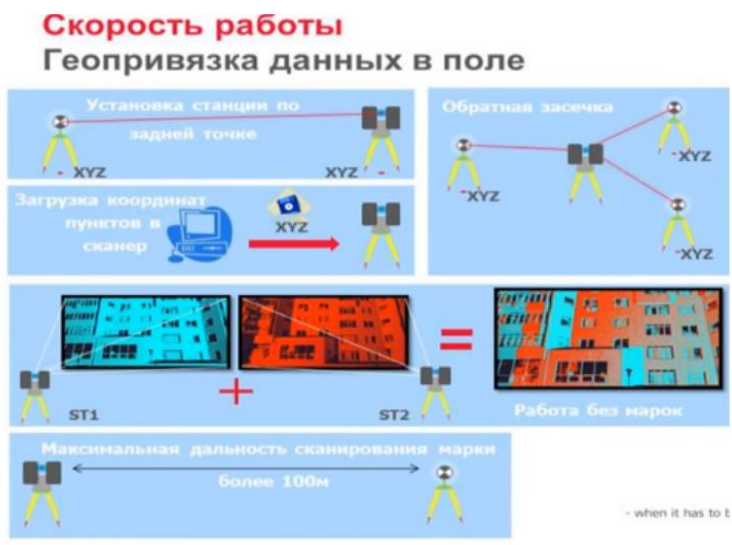

Рис. 3. Технологическая схема привязки в поле

Условия окружающей среды: включает несколько параметров: рабочая температура, температура хранения, пыле и влагозащита.

Температура хранения говорит пользователю, при какой температуре нельзя в принципе, выносить прибор на местность, при превышении диапазона рабочей температуры. [7 с. 26] (Т.к. это опасно, с той точки зрения, что существует большая вероятность сломать сканер, либо данные могут быть весьма искажены). 
Пыле и влагозащита. Основной проблемой на практике - это осадки. Если сканер может работать в дождь, то это большой плюс. И, опять же, осуществляя съемку объектов в промышленных цехах, в которых может быть сильная запыленность прибору нужна пылезащита.

Сервис и ремонт. Активная эксплуатация сканера приводит к раскалибровке. Калибровка/ремонт сканера в сервисном центре - долго и дорого. Поэтому следует выбирать сканеры, калибровать которые пользователю можно самостоятельно.

Программное обеспечение. Сшивка и геопривязка, обработка данных.

Какие способы сшивки/геопривязки должны поддерживаться: работ

1)Загрузка со сканера данных, геопривязанных в процесс полевых

2)Все способы геодезической привязки данных (по известной станции, обратная засечка и т.д.). [8 с. 77]

3)Сшивка без марок

4)Комбинация всех способов сшивки в одном проекте. [9 с. 56]

5)Возможность качественной сшивки больших проектов (десятки, сотни станций).

Обработка данных. После обработки данных, приходится работать в САПРах (Системах проектирования), поэтому очень важна интеграция. Для этого нужен легкий экспорт данных в САПР. [10 с. 152] Обработка данных должна быть максимально быстрой. Рекомендуется использовать специализированный СОФТ одного производителя.

Демонстрационный показ. Для демонстрации сканера продавцам нужно выбирать объекты со сложными элементами, которые Вы будете в перспективе сканировать. Т.е. если Вам нужно будет сканировать промышленный объект, и Вы знаете, что нужно будет отображать в 3D модели мелкие элементы (трубы и т.п.), то найдите подобный объект и посмотрите, как работает сканер. [11 с. 107] Что именно нужно требовать от компании, демонстрирующей сканирующую систему?

1)Несколько станций с разными типами сшивки данных

2)Детальное сканирование элементов с разных дистанций. (Чтобы реально посмотреть, как будут сканироваться те детали, и в каком контексте они будут нужны Вам. Следует обратить на минимальный размер детали, которая будет сканироваться).

3)Демонстрация процесса сшивки/геопривязки и обработки данных.

4)Демонстрация примера сшивки/геопривязки и обработки данных крупного объекта. [12 с. 127]

Исходя из вышеизложенного, выбор сканера нужно начинать с определения конкретной цели, как вы планируете его использовать. Вы должны для себя решить, какие основные задачи будут стоять перед вашим сканером. От этого очень сильно будет зависеть его цена. Ведь сканер - это очень интересная вещь, в том плане, что неграмотный пользователь может переплатить немалые деньги при покупке сканера за те его функции, которые он никогда в жизни использовать не будет. И правило "чем 
дороже, тем лучше", которое справедливо для многих компьютерных компонентов, таких, например, как оперативная память или жесткий диск, при покупке сканера просто не работает.

\section{References:}

[1] www.navgeocom.ru (дата обращения 29.12.2016)

[2] Вальков В.А., Мустафин М.Г. Геодезический контроль деформаций высотных сооружений на основе лазерного сканирования // Маркшейдерский вестник. 2015. № 2 (105). С. 24-28.

[3] Гайрабеков И.Г., Пимшин Ю.И. Определение деформации объекта с использованием наземного лазерного сканирования // Труды Грозненского государственного нефтяного технического университета им. академика М.Д. Миллионщикова. 2006. № 6. С. 171-177.

[4] Бушнева И.А., Безверхова А.Ю., Шевченко Г.Г., Гура Д.А. Об использовании наземного лазерного сканирования для получения фасадных чертежей исследуемых зданий и строений // Научные труды Кубанского государственного технологического университета. 2016. № 11. С. 89-97.

[5] Грибкова И.С., Шерстюк Н.А. Лазерное сканирование // В сборнике: Науки о земле на современном этапе VIII Международная научно-практическая конференция. 2013. С. 53-55.

[6] Шевченко А.А., Глазков Р.Е., Пилюшенко А.В. Принцип работы наземной сканирующей системы // Научные труды Кубанского государственного технологического университета. 2016. № 11. С. 76-88.

[7] Гура Т.А., Катрич А. Е. Обработка данных наземного лазерного сканирования для получения обмерных чертежей объектов культурного наследия // Молодой учёный Международный научный журнал, № 26 (130), 2016г, С. 25-28

[8] Кузнецова А.А., Гура Д.А., Алкачев Т.Э. Анализ полученных данных методом лазерного сканирования для выполнения периодического мониторинга на примере здания расположенного в г. Краснодаре // Статья в журнале: Научные труды Кубанского государственного технологического университета. 2014. № 4. С. 77-83.

[9] Гура Д.А., Верезубов Е.А. Мобильному миру - мобильные сканирующие системы // Сборник трудов конференции: Науки о земле на современном этапе. VIII Международная научно-практическая конференция. 2013. С. 56-58.

[10] Гура Д.А., Шевченко Г.Г. Экологический мониторинг деформации сооружений с использованием наземного лазерного сканирования // В сборнике: Строительство - 2010. Материалы Международной научно-практической конференции. Дорожно-транспортный институт. 2010. С. 152-153.

[11] Шевченко Г.Г., Гура Д.А., Глазков Р.Е., Пилюшенко А.В. Технологическая схема проведения фасадной съёмки методами наземного лазерного сканирования // Сборник трудов конференции: WORLD SCIENCE: PROBLEMS AND INNOVATIONS сборник статей III Международной научно-практической конференции. Пенза, 2016. С. 107-112

[12] Шевченко Г.Г., Гура Д.А., Глазков Р.Е. Анализ программного обеспечения для обработки данных наземного лазерного сканирования // Современное промышленное и гражданское строительство. 2016. Т. 12. № 3. С. 127-140. 